\title{
1 Stakeholder dynamics, perceptions and representation in a regional coastal \\ 2 partnership
}

3 Abstract

4 Effective stakeholder participation is increasingly seen as an essential part of improving 5 marine and coastal management. Coastal partnerships are a well-established informal 6 method for enabling stakeholder participation in coastal management. However, how well 7 they perform this role has been little explored. The North West Coastal Forum is a UK regional 8 coastal partnership, interacting with stakeholders from across local, regional, national and 9 international spatial scales. At the time of this research, the Forum had been in place for 14 10 years and, with its excellent record keeping, provided a valuable case study of the effectiveness of coastal partnerships to engage with and represent stakeholders over time.

12 This study both analysed Forum records and conducted an electronic survey of Forum members. The diversity of stakeholders that participate in the Forum and how that has changed over time was examined. Forum members' perception of the purpose of the Forum and their level of satisfaction with Forum performance was also investigated. In addition, we explored members' values and how they aligned with the organisations they were representing. Results indicated that, whilst many sectors have been represented on the Management Board and at Forum events, there are some which dominated, particularly Local Authorities, and others, such as extractive industries, which were under-represented. Overall, survey respondents' perceptions of the Forum purpose aligned with its stated purpose very well. Respondents were also supportive of the performance of the Forum: $56 \%$ considered the Forum to have delivered on initial expectations "well" or "very well" and only 4\% "poorly". Respondents' personal values tended towards pro-environmentalism and were broadly in line with the perceived values of their own host organisations, suggesting that stakeholder representatives can be effective conduits. This study indicates that coastal partnerships can be viewed by stakeholders as an effective means for facilitating stakeholder engagement. As such, coastal management efforts should encourage the development and ideally provide long term support for coastal partnership initiatives. However, this study also suggests that active recruitment is needed to encourage a full range of stakeholders to participate and thus enable coastal partnerships to more fully contribute to integrated coastal zone management. normal science; North West Coastal Forum; Values 
Until recent years, coastal zone management has predominantly been sectorally based, bound by administrative limits from a range of statutory bodies [1-3]. This sectoral approach has been criticised for a lack of connectedness and a confusion of regulatory authorities, resulting in inconsistent approaches to management, even in adjacent stretches of coast, and a particular lack of integration across the land-sea interface [1]. The failing of the sectoral management approach has often led to degradation of coastal areas [3-6]. Integrated coastal zone management (ICZM) is one way to address the disconnectedness of sectoral management and to fulfil the participatory requirements of international legislation. ICZM seeks to bring coherence to management approaches through consultative and deliberative approaches, public participation, and an ecosystem approach of management that spans land-sea-air interfaces [7]. In 2002 the European Parliament and the Council of the European Union officially adopted this approach and issued the 'Recommendation concerning the implementation of Integrated Coastal Zone Management' [8]. This paved the way for EU member states to adopt ICZM, following eight key principles laid down in the Recommendation. One of these principles focuses on participatory process in decision making, with the explicit inclusion of stakeholders.

Stakeholder participation has been shown to be valuable at all stages of coastal management. Involving stakeholders in planning processes has been shown to lead to better environmental decisions $[9,10]$ and enhanced compliance with a given management plan [11]. Stakeholder participation gives planners a greater appreciation of the context of a plan and the potential impacts of different planning options [12]. That can facilitate the early identification and thus more easy resolution of conflict associated with a potential plan [13], and can increase the range of solutions developed [10]. Incorporating stakeholder-derived data has also been shown to reduce the cost of planning solutions [14]. Despite the many positive reasons for involving stakeholders, there are nonetheless criticisms levied at participatory processes, such as: being too time-consuming, easily dominated by powerful voices, being consensus driven leading to stagnation, not enabling stakeholders to have truly meaningful input, and lacking in authority to effect change [4,10,15-17]. It has also been susceptible to bias and may not be representative of general public opinion [18], and the process of inviting stakeholders to represent single interests can exacerbate division, impeding solution development [19]. Increasing the diversity of voices being heard and encouraging more deliberative participatory approaches may therefore improve the practice of ICZM, and should thus be a focus of coastal managers.

There is now a range of deliberative participatory theories that merit application in coastal management decision-making situations, from cooperative and reflexive knowledge production, for example Mode 2 [20,21], right through to application and practice. Of particular relevance to the dynamic and unpredictable marine and coastal environment [22] is the theory of post-normal science (PNS). PNS is a deliberative theory advocated for 
application to 'wicked' problems, that is problems which hold uncertainty in their solutions and evidence, and for which there are high stakes and high risks. It contrasts with 'normal' science (according to Thomas Kuhn [23]) which takes a positivist approach in assuming that essentially all problems can be solved with enough data [24-26]. PNS advocates a plurality of voices and use of a range of knowledges, not just that which is derived from scientific method, and recognises the role of values in contemporary decision-making. Consequently it draws on aspects of environmental psychology, such as human and environmental values, in order to develop solutions to complex environmental and scientific problems occurring in a social setting.

Advocates for the application of PNS theory argue that it can help un-stall decision-making processes such as those found in sectoral management, by removing 'lack of evidence' as a problem [27], and by offering an alternative approach to resolve basic conflicts based upon different philosophical views [28]. Indeed Jones [28] argues:

"Given the divergent values of different stakeholders, the high degree of scientific uncertainty, and the high marine resource management decision stakes, it is concluded that a key challenge is to adopt a "middle-ground" approach which combines top-down and bottom-up approaches, and which is consistent with the post-normal scientific approach."

The right to participate in environmental decision-making is also enshrined in the 1998 Convention on Access to Information, Public Participation in Decision-Making and Access to Justice in Environmental Matters (the Århus Convention) [29], which stated that:

In order to contribute to the protection of the right of every person of present and future generations to live in an environment adequate to his or her health and well-being, each Party shall guarantee the rights of access to information, public participation in decision-making, and access to justice in environmental matters in accordance with the provisions of this Convention.

In the EU, the Convention has been ratified through a set of directives and regulations relating to public access to environmental information, planning, and justice (Directive 2003/4/EC [30]; Directive 2003/35/EC [31]; and Regulation (EC) No 1367/2006 [32]). Together with the Environmental Impact Assessment regulations, EU member states and the UK are obligated to engage the public on environmental matters. The means by which this should be performed is not exactly stipulated in the legislation, however the Århus Convention makes clear the role of NGOs in this process, as representatives of specific public environmental interests. Whilst the ability of NGOs to effectively represent the public has received criticism $[10,33,34]$, it's nonetheless the case that they now perform a pivotal function in UK and EU participatory environmental management, sending representatives to key local, national and international meetings and contributing directly to policy, for example, in the marine sector, coastal partnerships. 
111 Coastal partnerships are an established mechanism for facilitating stakeholder participation

112 and encouraging knowledge exchange between sectors [35,36], which in turn should

113 contribute to the achievement of more integrated coastal management. How effective

114 coastal partnerships are as a stakeholder participation mechanism has not, however, been

115 thoroughly examined. Here this gap is addressed by examining participation, satisfaction

116 levels, and values of the stakeholders involved in a well-established, regional coastal

117 partnership in the UK.

\subsection{Coastal management in the UK}

119 The UK makes a good case study for complex coastal management [37]. As a member of the

120 European Union (at present) and with devolved administrations within its borders, its

121 coastal areas are subject to legislation at a broad range of spatial scales [5,38]. A number of

122 government departments, non-government public bodies, and local authorities have an

123 interest in management, alongside the devolved administrations of Northern Ireland,

124 Scotland and Wales, whose remit extends to the $12 \mathrm{~nm}$ limit of inshore waters [39].

125 Traditionally the UK has managed coastal waters sectorally [2] but has made some progress

126 towards ICZM [39].

127 The 2009 Marine and Coastal Access Act [40] represented a firm step in the direction of

128 integrated management and compliance with the EU Marine Strategy Framework Directive

129 [41]. The Act requires authorities to produce a statement of public participation for any

130 marine planning activity, which includes people with an interest in the plan, and the general

131 public (Schedule 5, Paragraph 4). It also recognised the need to create a network of Marine

132 Conservation Zones (MCZs) [42] which led to nationwide regional consultation to identify

133 candidate sites.

134 Since the 1990s, a UK-wide, national network of local coastal partnerships has evolved as a

135 voluntary mechanism to coordinate the various actors involved in coastal governance [43].

136 These can be found at numerous coastal locations and vary in their scale, structure,

137 governance and legal identity, but share common features $[44,45]$. See Stojanovic and

138 Barker [44], Fletcher [43], and Fletcher et al. [46] for comprehensive descriptions of the

139 broader policy background to UK coastal partnerships.

140 These coastal partnerships can be defined as 'voluntary groupings of stakeholders and lay

141 public bound together by a shared sense of place concerning a discrete coastal area' [35]

142 and they have a well-established informal role in coastal decision-making based on ICZM

143 principles [47]. At the time of this research there were 42 coastal partnerships, which has

144 increased to more than 50 in 2018 [48]. However, they are suggestions of a general trend of

145 decline in UK coastal partnerships as a result of the changing marine policy landscape [46].

146 Only two of the 42 coastal partnerships were regional during the period of research, a

147 number since increased to eight. 
The North West Coastal Forum (hereafter the Forum) was the first regional coastal partnerships to be formed in the UK, and the only one operating in 2014 at a strategic level [44]. Though unusual in its regional scale, the functions it performs are common to other coastal partnerships in the UK, for example running regular conferences and workshops; small-scale project work and report writing; and serving as a hub for local organisations to network [44]. The Forum was established as result of recommendation from government funded research into integrated coastal planning, combined with the growing political interest in ICZM at the time [49]. Founded in 2000, the Forum was designed to address the principle of ICZM within the North West region of England, with its main aim being: "to promote and deliver integrated coastal zone management for the long term sustainability of the North West's coast". The Forum vision is focused on "three pillars of sustainability: Environment, Economics and Society." [50]. Prior to 2010 the Forum was hosted by the Government Office for the North West then the North West Regional Assembly. Since 2010, and at the time of this research, it was hosted by Sefton Council, but is now supported independently [51]. Throughout its history the Forum has depended upon mixed sources of funding, primarily grants or tied to project work (NWCF Secretariat, pers. comm.).

[Fig. 1 here.]

The Forum covers the North West coast of England, which runs for over $1000 \mathrm{~km}$ along the east of the Irish Sea and is bounded to the south by the North Wales coast (at the Dee Estuary) and to the north by the Solway Firth at the Scottish border (Figure 1). Administration and management of this coastal stretch is influenced by and shared with neighbouring administrations at local, national and international levels [2] including local authorities; the devolved administrations in Wales, Scotland and Northern Ireland; the Isle of Man and Ireland; and the EU and OSPAR. A variety of governmental and administrative bodies involved in policy-making, non-governmental organisations (NGOs) and groups also have considerable influence in the development and management of local policy [39].

Geographically, the North West coast has areas of considerable conservation and economic value and boasts a range of environmental and heritage designations. Prior to Marine Conservation Zone designation, over $30 \%$ of protected coast in England was within the North West. With the presence of ten ports, including major ones such as at Liverpool; energy installations (on and offshore); and popular tourist resorts attracting millions of visitors annually, the economy of the North West is heavily reliant on the coast [52]. Yet, around $80 \%$ of the coast remains undeveloped [2]. Balancing the needs of the growing number of coastal sectors in an integrated and sustainable way, whilst maintaining environmental integrity, is a substantial local challenge. recognised as an example of good practice, facilitating communication between partnerships and across the region [45]. Common to other UK coastal partnerships [44], the 
Forum is led by a management group and actions are primarily delivered by a single project officer, the Secretariat. The Management Board is open to all with an interest in coastal management, and is independent of those who have provided funding to the Forum. The Secretariat organises networking and knowledge exchange events for stakeholders within the North West region and more broadly, with both national and international attendees at some events. Together with the Management Board, the Secretariat performs other functions including commissioning research; digesting and disseminating national and international legislation and news; and providing considered and researched consultative responses on behalf of the stakeholders.

Like other coastal partnerships, the Forum is key to knowledge exchange within the geographical area it covers, and provides a voice to local and regional stakeholders in national policy (Forum secretariat, pers. comm.). Knowing which stakeholders are currently and have historically engaged with the Forum is important for understanding the reach of the Forum in the NW and the extent to which different interests are represented. In the interests of both ICZM and PNS there should ideally be a broad range of stakeholders engaged, from community residents, through industry, to statutory and government bodies. The make-up of engaged stakeholders may potentially impact upon the direction of decision-making in the region and consequently has the potential for influence at higher levels.

\subsection{Research Questions}

Specifically, this study set out to examine the following research questions:

1. What are stakeholders' perceptions of the Forum in provision of coastal partnership services?

2. What is the range of stakeholders that have been engaging with the Forum and how has representation changed over time?

3. What environmental values do Forum members hold and how do these relate to the perceived values of their host organisation?

\section{Method}

The North West Coastal Forum was selected as an appropriate case for this research it has been established for 17 years and has extensive records of participation over that time. These records were examined from inception to 2014. The examination of records was complemented with a survey of existing Forum members. As well as exploring stakeholder satisfaction with the Forum, stakeholder values and how these aligned with the perceived values of their organisation were also explored. The personal values that stakeholders hold are rarely considered in the literature on participatory processes, and how personal values may differ from the organisations individuals represent has not been explored. As these personal values may impact upon how representatives participate within the Forum, it is highly relevant when considering the efficacy of a stakeholder process. 


\subsection{Stakeholder representation}

226 The main form of engagement with the public and stakeholders is via the Forum's regular

227 events. The Forum keeps records of all event attendees: 21 events between 2004 and 2012.

228 The Forum also has records of members of the management board since its inception in

229 2000. These documents were analysed to determine historical stakeholder engagement.

230 Event attendees and board members were categorised by the type of organisation they

231 represented (19 categories) and by sector (61 categories) (Table 1).

232 Attendee classification was determined by internet research into the purpose or business of 233 the organisation, and cross-referenced with the Forum's own database classification. Single 234 organisations covering a range of fields were classified using Secretariat knowledge of their 235 reason(s) for engagement with the Forum at a given event. Classification of each 236 organisation was then used throughout all analyses.

237 [Tab. 1 here $]$

238 Management board member categorisation used data included in annual report publication and board meeting attendee lists. For analysis of overall type of organisation management

240 board members represented, both sets of data were combined. However, for analysis of change in representation of organisational type over time each data set was considered in

242 isolation, enabling the examination of difference between those named as on the board and

243 those who actively attended meetings. Events attendees and board members whose

244 organisational type could not be identified at all were categorised as various.

245 Event attendance over time was analysed according to event, whereas management board 246 membership was considered on an annual basis. Attendees who were not present as a 247 stakeholder (e.g. translators, presenters) were excluded from analyses. Individuals in 248 attendance as stakeholders of more than one organisation had their attendance value split across the relevant organisational types. For example, a representative of a business at a single meeting was allocated a value of 1 ; a representative of both a community group and a consultancy was allocated 0.5 to each type or sector.

\subsection{Stakeholder survey} In 2014, an online survey was sent to the Forum stakeholder list which was composed of previous event attendees, current or former management board representatives, and any additional individuals who had requested to be on the Forum mailing list. The survey distribution method was chosen on the basis that the Forum Secretariat typically communicated via email and the survey could be cheaply and effectively distributed to all stakeholders. A news article about the research was placed on the website inviting participation but it elicited no responses. (See Supplementary S1 for complete survey.) questions, but included some qualitative questions. The survey sought to identify the 
organisation type (e.g. business) and sector (e.g. fishing) of each stakeholder and gather general demographic information about the individuals. It also aimed to uncover opinions on the purposes (as replicated from the Coastal Partnerships Network report to enable direct comparison with the Forum's stated purpose [45]) and efficacy of the Forum, and assess the environmental values of stakeholders and their host organisations, as perceived by the stakeholders. Respondents had the option to respond in a personal capacity and those respondents were not included in any analyses comparing personal and organisational values. The survey requested organisation type and sector information via multiple choice, plus an 'other' field.

\subsection{Value statement analysis}

272 A large section of the online survey considered respondents' different value positions in the context of coastal zone management, to allow comparison between values and other characteristics such as organisational sector, political position, educational level etc. Respondents were provided with a five-point Likert scale (strongly agree-strongly disagree) and a 'don't know' option. Using this scale they were asked to rate a series of value statements, which were constructed to reflect conflicting values between environmental, economic and social issues (See Supplementary S2 for a full list). These were chosen to reflect a diversity of pro- and anti- positions: science, localism, community participation, environmental protection and conservation, economic priority. These values were considered to be important for conflict resolution and coastal zone management, and also contribute to an understanding of how post-normal science might be prevalent in or useful to this method of stakeholder engagement. The first set of statements was repeated, asking for both personal and organisational perspectives, allowing a comparison between organisational and personal values to explore how well aligned these were. The second set of value statements were asked from a personal perspective only. The rationale for this approach was that many of the relationships within the Forum were based on the individual rather than the organisation, as demonstrated by changing levels of commitment with changes in staff (North West Coastal Forum, pers. comm.). It is probable therefore, that personal values are significant in shaping the way the Forum and stakeholders influence one another.

\subsection{Data analysis}

293 Qualitative questions were manually mapped thematically and coded for emergent common themes. Likert scales were converted to numbers for analysis (very well $=5$ to very poorly=1; strongly agree $=5$ to strongly disagree $=1 ;$ don't know $=0$ ). Statistical tests were performed in and organisational values; Wilcoxon Signed Ranks was used to test difference. 


\section{Results}

299

300

301

302

303

304

305

306

307

308

309

310

311

312

313

314

315

316

317

318

319

320

321

322

323

324

325

326

327

328

329

330

\subsection{Stakeholder representation}

\subsubsection{Forum events}

Attendees at events came from a broad range of organisation types and sectors. In total, 379 organisations were represented at one or more of the 21 events. 203 organisations sent only one representative to a single event but many organisations sent multiple representatives. Local authorities sent the most individuals, a total of 94.5 out of 1484 people at all events combined, representing 53 authorities. However, at an organisation level, businesses were the most highly represented $(34 \%, n=130)$ followed by local authorities (14\%, $n=53$ ). Academics, NGOs, partnerships ${ }^{1}$ and government agencies showed similar representation (8.7\%, 8.4\%, 8.2\% and $7.7 \%$ respectively). Regional government and regional agencies, projects ${ }^{2}$, town council and education were least represented with only one or two organisations each, though it is to be expected for regional organisations to be small in number compared to multiple organisations working at smaller scales.

Events each had a theme and examination of attendance gives an indication of thematic interests of each type of organisation. Education, projects, regional government and town council were only represented at one event each, on specific themes of sustainability/community interest. Conversely, NGOs were represented at all 21 events and government agencies and local authorities and partnerships at 20; unsurprising for organisations with statutory duties and/or sweeping interests in the marine and coastal environmental management. Event themes that were highly focused attracted a smaller number of attendees and frequently a majority of businesses.

Changes in representation of these different types of organisation over time were analysed and the findings are presented in Figure 2 (note some types were combined for ease of presentation). Some organisation types have held a fairly consistent proportion of representation, such as NGOs, charities, and government agencies. Local authorities dominate the chart, largely because of the multiple individual representatives previously discussed. Of note is the greater involvement of voluntary organisations in recent years. These are not charities, which are classified separately, but community organisations representing local issues, for example friends groups. This pattern may reflect attractiveness to individuals and voluntary groups of specific themes, e.g. marine spatial planning, or may indicate a growing trend of more community involvement in participatory processes at the Forum that would warrant further investigation, which is considered further in the

\footnotetext{
${ }^{1}$ Partnership refers to collaborative groups that are not an organisation or short-term project but which generally house representatives from a number of different organisations with interest in a particular location or activity. They are distinct from loose voluntary organisations which are comprised of interested members of the public rather than organisations.

${ }^{2}$ A representative of a time-limited discrete project not coordinated by any specific organisation.
} 
discussion. There has been an overall increase in proportion of attendees classified as various since around 2009 (combined with 'other' category in Figure 2). This may also indicate a diversification of the stakeholders getting involved with the Forum to include more members of the public.

[Fig. 2 here]

Analysis of attendees by sector provided a more sensitive picture of representation at events. Those in the bottom two quartiles included the following industries: dredging $(n=1)$, transport - air $(n=1)$, transport - sea $(n=1)$, transport - land $(n=2)$, boating $(n=3)$, construction $(n=3)$, defence $(n=3)$, and energy (non-renewable) $(n=3)$. The top quartile (shown in Figure 3 ) was dominated by local authority $(n=49)$. It also included environment $(n=24)$, engineering $(n=19)$, scientific research $(n=18)$, renewables $(n=17)$, and conservation $(n=17)$. Fisheries $(n=14)$ also appears in the top quartile. The high presence of environmental, conservation and scientific sectors may influence the perception of the Forum.

[Fig. 3 here]

\subsubsection{Management Board}

The management board acts as a steering group and has the most significant influence on the activities of a coastal partnership [47]. Over the course of the Forum a total of 55 organisations have been represented on the Board. The most commonly represented sectors, by organisation, are partnership $(n=13)$, local authority $(n=11)$, government agency $(n=7)$, and business $(n=5)$. Unlike with the event attendee data, the management board data included roles of local authority representatives enabling a more specific sectoral analysis. Only 19 of the 61 sectors identified in the events analysis were represented on the board (Figure 4). Most highly represented were regeneration ( $n=12)$, coastal defence $(n=7)$, Local Coastal Partnership ( $n=7)$ and environment $(n=5)$. Some notable exceptions include aggregates, boating, and sailing. Planning, marine spatial planning, community and countryside, all listed in the top quartile of subsectors in the survey data, may be covered to some extent within the regeneration, conservation and government categories for Board members' roles. There were no members of the public or community organisations present on the board at any time in its history. Only large national charities were present from the voluntary sector. Board membership is open to anyone who is a stakeholder and who wishes to get involved, therefore the limited representation is not a function of direct selectivity by the Forum.

[Fig. 4 here]

Unlike the variation present in event attendees, the board membership showed a relatively static distribution of sectoral representation over time with changes predominantly driven by institutional changes in organisations. However, actual attendance at board meetings did 
show some temporal diversity (Table 2). Whilst Government authorities and agencies have remained a steady presence, possibly connected to the Forum's origins within regional government, more diversity has been seen in representation of other sector types. For example, concurrently with the establishment of the UK Marine Management Organisation (MMO) in 2010 and a period of consultation which may have both raised awareness of the Forum amongst other individuals and groups, or provided an avenue for others to gain timely influence in local coastal management.

[Tab. 2 here]

\subsection{Survey}

After removal of bounced emails and duplicates the final number of email addresses in receipt of the survey was 1284 and 125 responded. A number of recipients may no longer have been involved with the Forum despite being on the list, and two emails were received indicating this to be the case. For this reason it is difficult to calculate an accurate response rate against recipients still engaging with the Forum. Not all respondents completed all questions and the sample set for most value questions was in the region of 80 .

The survey data provides a snapshot of the stakeholders represented at the Forum through event attendance or interest. Respondents were given a concise list of organisation types to select from which was compared to the sectoral analysis of the event attendee lists. Grouping the event attendee data into this smaller range and plotting against the survey data showed a broadly similar distribution indicating a satisfactory degree of consistency in organisation classification across the data sets (Figure 5).

[Fig. 5 here]

Of the 61 sectors identified in the Forum documents, 58 were represented within the survey respondents. Three government agency/government respondents selected 23-24 sectors indicating the breadth of issues of interest to some large organisations. The majority of respondents selected only one $(n=63)$ or two $(n=19)$ sectors indicating that most stakeholders represent single issues. Other sectors additionally provided included marinas, museums, advocacy, European NGO, reduction of litter, development of coastal path. Sectors selected by only a single respondent (including building surveyors; defence (MOD); fish wholesale; international partnership; marine engineering consultancy; meteorology; real estate; shipping; and telecoms) are not heavily involved with the Forum. Some of these, together with aggregates in the bottom quartile, are important sectors for marine planning.

\subsubsection{Perceptions of the Forum}

The survey examined respondents' perceptions of the Forum, both efficacy and purpose, as well as their reasons for participation. $36 \%(n=27)$ of respondents indicated their professional role was the leading reason for participating; $26 \%(n=20)$ cited a general or local interest in coastal conservation and/or management. $16 \%(n=12)$ had attended an 
event as first contact with the Forum. The remaining reasons could be classified as project based, networking, board election, personal invitation, or involvement with its inception.

On the whole respondents were highly satisfied with the Forum: $56 \%(n=43)$ considered the Forum to have delivered on initial expectations well or very well. Only $4 \%(n=3)$ felt the Forum had delivered poorly. 73\% (59) of respondents strongly agreed or agreed that the Forum is a "neutral, broad and honest broker". This is important because most respondents $(81.7 \%, n=67)$ considered the Forum's purpose "to provide broadly based consultative forum on the coast" - the most highly selected of 8 purposes (Figure 6). Only 19 respondents (23.2\%) identified 'meeting statutory requirements' as a purpose of the Forum, and this was the only purpose that the Forum did not self-identify with in the Coastal Partnerships Network Report [45]. Surprisingly 'to drive a partnership approach to coastal issues' was the least chosen purpose, only chosen by 5 respondents (6\%).

[Fig. 6 here]

Respondents were given a list of services the Forum could offer as a coastal partnership and asked to rate how successfully the Forum had delivered them. Figure 7 shows that the majority of services were favourably rated. The least favourable rating ('poorly' + 'very poorly') was 'Community engagement and awareness raising' at $11.8 \%(n=11)$. In the Coastal Partnerships Network Report [45] this was the only service that the Forum itself did not list as providing.

[Fig. 7 here]

Overall, the Forum was viewed positively as an effective provider of services that met the expectations of stakeholders. Thus as coastal managers and policy makers aim to involve stakeholders in the development of more integrated management and meet national and international obligations for participation, developing and expanding voluntary coastal partnerships is one potentially effective option.

\subsubsection{A comparison of Forum stakeholder personal and perceived organisational values}

Respondents were provided with a set of values relating to a range of environmental perspectives including the influence of science, localism, economics, and environmental protection (see Supplementary 2). They were asked to respond from both a personal perspective ( 77 responded) and what they believed were their organisation's perspective (81 responded). The grouped data for each value clearly showed a similarity of distribution between the two sets when plotted on a frequency chart and the non-parametric Spearman correlation was used to ascertain the degree of similarity. Results of the Spearman analysis showed positive correlation between personal and perceived organisational values for all 12 value statements $\left(r_{\mathrm{s}}\right.$ values: $\mathrm{V} 1=0.687 ; \mathrm{V} 2=0.597 ; \mathrm{V} 3=0.66 ; \mathrm{V} 4=0.716 ; \mathrm{V} 5=0.397 ; \mathrm{V} 6=0.478$; $\mathrm{V} 7=0.781 ; \mathrm{V} 8=0.582 ; \mathrm{V} 9=0.515 ; \mathrm{V} 10=0.657 ; \mathrm{V} 11=0.735 ; \mathrm{V} 12=0.580, \mathrm{p}<0.001$ in all cases). In such emotive fields as environmental management and exploitation it is not surprising that 
people choose to work for organisations they believe broadly share their own values. People

443 pursuing education to a high level may be more likely to do so in order to pursue their own

444 interests and values in a career context and over half $(56 \%, n=46)$ of respondents were

445 educated at post-graduate level and another third $(32 \%, n=26)$ to degree level.

446 A small number of value statements showed some slight variation in distribution between

447 personal and perceived organisational values and the Wilcoxen Signed Ranks test of

448 difference was applied to the data. Only one value had a result significant to $p<0.05$ : Value

44910 "We should take full advantage of coastal and marine resources and exploit them to their

450 full potential" $(z=-2.123, p=0.034)$. Examination of the data showed that 8 respondents

451 rated this personal value higher up the scale of agreement than for their organisation; 38

452 rated their agreement equally for personal and organisational perspectives; and 20 rated

453 their agreement with this statement as less than that of their organisation. These results

454 imply that on this issue of exploitation of resources, a significant number of respondents

455 believed their organisation was more in favour of exploitation of the marine and coastal

456 resources than they were themselves.

457 To examine overall group agreement and disagreement, all values were plotted as

458 frequency histograms and skewness calculated. Values highly or moderately skewed

459 towards agreement or disagreement are shown in Table 3. All statements that were highly

460 skewed were so towards agreement with values that were pro-environmental; pro-science;

461 accepting of organisational responsibility; inclusive of all stakeholders; and balanced in

462 terms of social, socio-economic and environmental importance. Eight of these were

463 personal values, and three organisational values, suggesting that respondents' personal

464 values were more favourable towards a pro-environmental and pro-participatory position

465 than were the perceived values of their host organisations. There was some evidence to

466 suggest that individuals were less pro-exploitation that the organisations they represented.

467 V10, a pro-exploitation statement, was moderately skewed towards disagreement for both

468 personal and organisational responses, as was a further pro-exploitation statement, though

469 both were the least skewed of this set. There was a strong personal and organisational

470 tendency towards taking a balanced approach to coastal management. Differences between

471 personal and organisational values suggested that respondents may believe that

472 responsibility lies more with organisations than with individuals (V5O, V5P, and V9P).

473 [Tab. 3 here]

\section{4. Discussion}

475 Participatory decision-making is increasingly recognised as important for effective marine 476 and coastal environmental policy [9,14,46-48]. There is both legislative imperative $[8,29]$

477 and evidence from research and practice $[9,10,18]$ that public participation makes for better

478 decisions and problem-solving. Deliberative theories, such as post-normal science (PNS),

479 argue that complex environmental problems cannot be solved by the application of science 
alone, and scientific evidence must be used alongside other kinds of knowledge in order to produce the best solutions $[10,24]$. Coastal partnerships are designed to facilitate stakeholder participation and knowledge sharing. This research explored the efficacy of a regional coastal partnership, the North West Coastal Forum, and considered: the diversity of stakeholders that engaged with the Forum, their values and their level of satisfaction with the partnership.

486 The Forum's purpose was well understood and highly approved of by stakeholders. A wide range of stakeholders engaged with the Forum, but some sectors dominated in number of both individual organisations and individual representatives. There were temporal variations in stakeholder sector engagement related to event themes and time-limited projects, and there was a tentative pattern of increasing involvement from grass roots and community groups, amongst the local authority and business-dominated representatives, though this did not translate to the management board. Stakeholders considered the Forum an effective service provider. There was a pro-environmental tendency amongst engaged stakeholders and, in general, there were shared values between organisation and representative.

Voluntary coastal partnerships such as the Forum have been seen as a stage in the evolution of ICZM, with a recognised value in nurturing the ethos of ICZM where no statutory authority exists to deliver it [6]. The utility of coastal partnership has however been highly criticised by some [6] and realising their potential is not easy. This study shows that coastal partnerships can be successful, at least from the perceptions of the stakeholders that engage with it. The Forum has maintained a steady presence for 14 years, engaged with a large number of stakeholders from a broad mix of sectors; delivered regular, well-attended events focused on cross-sector issues; and provided a range of services that are both recognised by the stakeholders and perceived as being effectively delivered. As such our findings support the potential of coastal partnerships to contribute to evolving ICZM. The future for partnerships such as the Forum may be as advisory authorities to statutory structures with an ICZM function, with their remit of involving and informing individuals on coastal issues [6]. Complementary to this role, local and regional coastal partnerships, such as the Forum, can support effective integration of information systems within decisionmaking [57].

511 Coastal partnerships have been criticised for exaggerating claims of stakeholder

512 involvement $[35,36,44]$, yet our findings show that the Forum both succeeded in obtaining 513 diverse stakeholder involvement in numerous events held over a 14 year period and 514 succeeded in terms of stakeholders satisfaction for delivering on expectations. Thus is 515 seems that in general the Forum is effective at engaging and involving stakeholders. Indeed, 516 it has been previously identified that internal constraints are the primary cause of coastal 517 partnership inefficacy, particularly the time diverted to securing funding $[44,58]$. Thus, lack 
of dedicated long term funding may what hold coastal partnerships back, not their ability to

519 engage stakeholders.

520 The diversity of stakeholders that engage with coastal partnerships has implications for the 521 partnerships capacity to contribute to integrated management. One of the big criticisms of

522 stakeholder participatory structures is the risk that some voices will dominate discussions

523 and positions at the expense of others [4,6]. Here, whilst the Forum engaged with a broad

524 suite of stakeholders, local authority and certain businesses tended to dominate both

525 events and the management board, in terms of numbers. Underlying causes for this might

526 include the historical involvement of regional and local government in hosting the Forum, or

527 may reflect the importance of the Forum to local government as a means of contributing

528 ICZM to statutory responsibilities. The far lower representation of industries that have a

529 significant impact on marine environmental health, such as aggregate extract, may limit the

530 capacity of the Forum to contribute to integrated management. The comparative lack of

531 diversity in engagement on the management board responsible for steering the coastal

532 partnership is also cause for concern, and opens the Forum to the risk of perceptions that it

533 is biased. Though the board has open membership, the lack of representation of many

534 groups suggests there are barriers to participation in this leadership role, which warrants

535 further exploration. However, that results also show that new and more diverse

536 organisations were engaged through thematic events is promising and indicates that coastal

537 partnerships can encourage wider engagement though a strong diversity of events, with

538 themes tailored to target stakeholders.

539 The post-normal science approach indicates representation of differing types of knowledge

540 and values in order to develop better solutions and can be applied to complex coastal issues

541 [59]. By bringing together decision-makers and a wide range of stakeholders and publics,

542 the Forum offers decision-makers the opportunity to better understand the context in

543 which they are making decisions and in so doing continues to meet its objective of being a

544 "broadly based consultative forum on the coast" [45]. The Forum is also contributing to the

545 EU Recommendation on ICZM [8], which stipulates engagement of "economic and social

546 partners, the organisations representing coastal zone residents, non-governmental

547 organisations and the business sector", by facilitating stakeholder representation from a

548 considerable range of coastal interests.

549 In considering representation, this study looked at organisational interests, which are

550 important and highly significant, particularly in terms of statutory responsibilities and

551 impacts upon the environment. Post-normal science theory would, however, go a step

552 further in advocating direct involvement of stakeholders, not just of organisations, but of

553 the public themselves, as not only coastal zone residents and businesses are affected or

554 interested in marine health. Unlike attendance as an organisational representative,

555 individual attendance incurs personal cost (time and expenses). To encourage participation

556 from individuals from the general public the Forum and other coastal partnerships may 
need to adapt their engagement mechanisms. Holding events at the weekend, for example, may enable more individuals to attend, but may conversely make attendance more difficult for others, such as members of the civil service. Another possible way of improving attendance of less well represented groups, be they individuals, fishers, or community groups, could be facilitated through additional funding utilised in subsidising costs of attendance [16].

Respondents, in general, reported similar values to the stakeholder organisations that they represented. The relationship between a stakeholder organisation (or constituency) and its representative is considered fundamental to the flow of views to a coastal partnership, and there is a risk that an individual will represent their own views rather than those of the organisation they represent, consciously or subconsciously [47]. Here we showed a very strong association between personal and perceived organisational values, indicating that professionals either grow to align with their organisational aims or, perhaps more likely for environmental professions, individuals choose to work for organisations which broadly reflect their personal values. Whilst there is limited existing research exploring this connection in the environmental sector, one study found that good ecological credentials makes companies more attractive as prospective employers, though the study found no connection between an individual's ecological values and attractiveness of an employer by its ecological statement [60]. The good alignment of personal and organisational values demonstrates that individuals present at Forum events are likely to be strong representatives for their organisation's values and contribute to the decision-making process in a way which is relevant to their organisation's aims, provided that their perception of organisational values is accurate.

The deficit in representation from extractive industries and the general public is of particular concern for a partnership aiming for ICZM and one common to other coastal partnerships $[35,36,44]$. Though results here show that the members of the Forum consider it to be a neutral, honest broker, the Forum appears to suffer from a perception of pro-environmental leaning (North West Coastal Forum, pers. comm.), which may negatively influence attendance by some industries. A perception of pro-environmentalism may discourage some stakeholders and they may not feel they will get an equal voice or fair hearing. Alternative explanations for lower participation of extractive industries might be perceived significance of the Forum [47] or barriers to attendance. The pro-environmental leanings of the Forum may, in part at least, be the result of attendance of stakeholders that are motivated and financially able to attend, rather than be representative of all those who have an interest. It may also be that different methods of communication are needed to engage with some sectors, such as fishing [16]. Active recruitment of underrepresented sectors may help to alleviate perceptions of bias and increase the capacity of the Forum to represent the full suite of coastal sectors. Again, targeting events to appeal to these underrepresented groups may also be useful. 
This research was made possible in part by the excellent historical record keeping of the Forum and provides an informative temporal analysis of stakeholder participation, values, and perceptions of the Forum. The knowledge that some sectors are attracted to events of particular themes (Figure 2) enables coastal partnerships to reflect on their stakeholder engagement processes and target efforts to engage under-represented sectors. Research such as this may also support funding applications as evidence of effective performance.

This study focused on a regional coastal partnership and some caution should be exercised about applying the potential issues of under representation of extractive industries and the general public to other partnerships, which work across different scales. Indeed, local CPs may engage stakeholders differently. However, our findings of low representation of certain industries is common to other research $[35,36,44]$ and future studies should explore in more detail the incentives and barriers to stakeholder engagement with coastal partnerships, which in turn can inform coastal partnerships policies and activities.

\section{Conclusions}

Coastal partnerships can be effective in delivering a wide range of services that promote integrated coastal zone management via engagement with a varied stakeholder base. In particular, this work shows that coastal partnerships can bring stakeholders together and facilitate dialogue in a way that stakeholders are satisfied with. However, this study has highlighted a risk that coastal partnerships may fail to engage with the full range of stakeholders and, with that shown, the potential that their utility will be limited as a result. Indeed, it is within the most contentious areas of conflict, bringing together historically opposed stakeholder groups, where coastal partnerships could offer the greatest benefit. The lower participation by extractive industries shown here represents a missed opportunity for dialogue between these industries, conservation-focused stakeholders, and policymakers. Potential perceptions of bias within coastal partnerships may limit the range of stakeholders that engage, but engagement may also be affected by a range of perceived or real barriers, such as cost. Future research should address the challenging question of how coastal partnerships can influence higher decision-making levels, and what influence, therefore, is exerted by the composition of stakeholders engaged in the partnership.

Ultimately, at least initially, coastal partnerships may need to invest in active recruitment of under- and unrepresented groups. This inevitably requires resourcing: more staff or volunteer time, flexibility in events and their timing/location, and allocation of sufficient funding to remove logistical barriers. However, more complete representation of the full range of coastal stakeholders will improve the ability of coastal partnerships to facilitate comprehensive knowledge exchange and ultimately contribute to more integrated management. Thus, whilst coastal partnerships may be an effective way to encourage stakeholder participation, adequate resourcing guaranteed over extended timeframes will be needed for coastal partnerships to reach their potential in terms of contributing to ICZM. 
635

636

637

638

639

640

641

642

643

644

645

646

647

648

649

650

651

652

653

654

655

656

657

658

659

660

661

662

663

664

665

666

667

668

669

670

671

672

673

674

675

676
With thanks to Caroline Salthouse, Secretariat and Project Manager at the North West Coastal Forum for access to data, personal communications, and acting as mediator between authors and stakeholders, without whom this research could not have been performed. Appreciation is expressed to those stakeholders who completed the pilot survey and provided feedback, and all respondents who completed the stakeholder survey in order to support this research. Our thanks also to Professor Andrew Cooper, from the University of Ulster, and Dr Beverly Clarke, who provided feedback on an earlier version of this manuscript, and Rachel Lapota for feedback on questionnaire design.

This research did not receive any specific grant from funding agencies in the public, commercial, or not-for-profit sectors.

\section{References}

[1] A.M. O'Hagan, J.A.G. Cooper, Spatial variability in approaches to coastal protection in Ireland, Journal of Coastal Research. SI 36 (2002) 544-551.

[2] R. Ballinger, G. Lymbery, ICZM in the North West of England - an example of the assessment and implementation of ICZM at a sub-national, regional scale, in: Integrated Coastal Zone Management: Theory and Practice, , Forkiewicz, M. (Ed.), Gdańsk University of Technology, Faculty of Management and Economics, Gdańsk, 2006: pp. 916.

[3] L.B. Crowder, G. Osherenko, O.R. Young, S. Airamé, E.A. Norse, N. Baron, J.C. Day, F. Douvere, C.N. Ehler, B.S. Halpern, S.J. Langdon, K.L. McLeod, J.C. Ogden, R.E. Peach, A.A. Rosenberg, J.A. Wilson, Sustainability. Resolving mismatches in U.S. ocean governance, Science. 313 (2006) 617-618. doi:10.1126/science.1129706.

[4] J. McKenna, A. Cooper, Sacred cows in coastal management: the need for a 'cheap and transitory' model, Area. 38.4 (2006) 421-431.

[5] K. Yates, A. Payo Payo, D. Schoeman, International, regional and national commitments meet local implementation: A case study of marine conservation in Northern Ireland, Marine Policy. 38 (2013) 140-150.

[6] J. McKenna, A. Cooper, The role of voluntary coastal partnerships in ICZM, in: D.R. Green (Ed.), Coastal Zone Management, Thomas Telford, London, England, 2009: pp. 307-334.

[7] J. Sorensen, National and international efforts at integrated coastal management: definitions, achievements, and lessons, Coastal Management. 25 (1997) 3-41.

[8] The European Parliament and the Council of the European Union, Recommendation of the European Parliament and of the Council of 30 May 2002 concerning the implementation of Integrated Coastal Zone Management in Europe, 2002. http://eurlex.europa.eu/LexUriServ/LexUriServ.do?uri=OJ:L:2002:148:0024:0027:EN:PDF.

[9] M.S. Reed, Stakeholder participation for environmental management: A literature review, Biological Conservation. 141 (2008) 2417-2431. doi:10.1016/j.biocon.2008.07.014.

[10] J. Steele, Participation and Deliberation in Environmental Law: Exploring a Problemsolving Approach, Oxford J Legal Studies. 21 (2001) 415-442. doi:10.1093/ojls/21.3.415.

[11] J.E. Innes, Planning through consensus building: A new view of the comprehensive planning ideal, Journal of the American Planning Association. 62 (1996) 460-472. 
[12] K.L. Yates, D.S. Schoeman, Spatial Access Priority Mapping (SAPM) with Fishers: A Quantitative GIS Method for Participatory Planning., PloS One. 8 (2013) e68424. doi:10.1371/journal.pone.0068424.

[13] R. Pomeroy, F. Douvere, The engagement of stakeholders in the marine spatial planning process, Marine Policy. 32 (2008) 816-822. doi:10.1016/j.marpol.2008.03.017.

[14] K.L. Yates, D.S. Schoeman, Incorporating the spatial access priorities of fishers into strategic conservation planning and marine protected area design: reducing cost and increasing transparency, ICES J Mar Sci. 72 (2015) 587-594. doi:10.1093/icesjms/fsu122.

[15] J. Turnpenny, I. Lorenzoni, M. Jones, Noisy and definitely not normal: responding to wicked issues in the environment, energy and health, Environmental Science \& Policy. 12 (2009) 347-358. doi:10.1016/j.envsci.2009.01.004.

[16] K. Yates, View from the wheelhouse: Perceptions on marine management from the fishing community and suggestions for improvement, Marine Policy. 48 (2014) 39-50.

[17] K.L. Yates, Meaningful stakeholder participation in marine spatial planning with offshore energy, in: K.L. Yates, Bradshaw, C.J.A. (Eds.), Offshore Energy and Marine Spatial Planning, Routledge Publishers, Earthscan Series, 2018. doi:10.4324/9781315666877-10.

[18] K. Sayce, C. Shuman, D. Connor, A. Reisewitz, E. Pope, M. Miller-Henson, E. Poncelet, D. Monié, B. Owens, Beyond traditional stakeholder engagement: Public participation roles in California's statewide marine protected area planning process, Ocean \& Coastal Management. 74 (2013) 57-66. doi:10.1016/j.ocecoaman.2012.06.012.

[19] M. Pieraccini, Rethinking Participation in Environmental Decision-Making: Epistemologies of Marine Conservation in South-East England, J Environmental Law. 27 (2015) 45-67. doi:10.1093/jel/equ035.

[20] M. Gibbons, C. Limoges, H. Nowotny, S. Schwartzman, P. Scott, The New Production of Knowledge: The Dynamics of Science and Research in Contemporary Societies, 1 edition, SAGE Publications Ltd, London; Thousand Oaks, Calif, 1994.

[21] H. Nowotny, P. Scott, M. Gibbons, Re-thinking science: mode 2 in societal context, (2003).

https://pdfs.semanticscholar.org/2515/62176a6d258710266edd7a5f51c819034d56.pdf (accessed September 10, 2018).

[22] M. Cordier, J.A.P. Agundez, M. O'Connor, S. Rochette, W. Hecq, Quantification of interdependencies between economic systems and ecosystem services: An input-output model applied to the Seine estuary, Ecol. Econ. 70 (2011) 1660-1671. doi:10.1016/j.ecolecon.2011.04.009.

[23] T.S. Kuhn, I. Hacking, The Structure of Scientific Revolutions: 50th Anniversary Edition, 4 edition, University Of Chicago Press, Chicago ; London, 2012.

[24] S.O. Funtowicz, J.R. Ravetz, Science for the post-normal age, Futures. 25 (1993) 739755. doi:10.1016/0016-3287(93)90022-L.

[25] J. Ravetz, S. Funtowicz, Editorial: Post-Normal Science-an insight now maturing, Futures. 31 (1999) 641-646. doi:10.1016/S0016-3287(99)00023-3.

[26] J.R. Ravetz, "Climategate" and the maturing of post-normal science, Futures. 43 (2011) 149-157. doi:10.1016/j.futures.2010.10.003.

[27] M. Giampietro, K. Mayumi, G. Munda, Integrated assessment and energy analysis: Quality assurance in multi-criteria analysis of sustainability, Energy. 31 (2006) 59-86. doi:10.1016/j.energy.2005.03.005. 
[28] P.J.S. Jones, Marine protected area strategies: issues, divergences and the search for middle ground, Rev. Fish. Biol. Fish. 11 (2002) 197-216. doi:10.1023/A:1020327007975.

[29] United Nations Economic Commission for Europe, Convention on Access to Information, Public Participation in Decision-making and Access to Justice in Environmental Matters, 1998.

[30] EC, Directive 2003/4/EC of the European Parliament and of the Council of 28 January 2003 on public access to environmental information and repealing Council Directive 90/313/EEC, 2003.

[31] EC, Directive 2003/35/EC of the European Parliament and of the Council of 26 May 2003 providing for public participation in respect of the drawing up of certain plans and programmes relating to the environment and amending with regard to public participation and access to justice Council Directives 85/337/EEC and 96/61/EC, 2003.

[32] EC, Regulation (EC) No 1367/2006 of the European Parliament and of the Council on the application of the provisions of the Aarhus Convention on Access to I nformation, Public Participation in Decision-making and Access to Justice in Environmental Matters to Community institutions and bodies, 2006.

[33] M. Lee, Access to Justice at EU Level in Environmental Law, Social Science Research Network, Rochester, NY, 2012. https://papers.ssrn.com/abstract=2062252 (accessed November 15, 2016).

[34] C. Nadal, Pursuing Substantive Environmental Justice: The Aarhus Convention as a 'Pillar' of Empowerment, Environmental Law Review. 10 (2008) 28-45.

[35] S. Fletcher, Stakeholder representation and the democratic basis of coastal partnerships in the UK, Marine Policy. 27 (2003) 229-240.

[36] S. Fletcher, K. Pike, Coastal management in the Solent: The stakeholder perspective, Marine Policy. 31 (2007) 638-644. doi:10.1016/j.marpol.2007.03.010.

[37] T.A. Stojanovic, R.C. Ballinger, Integrated Coastal Management: A comparative analysis of four UK initiatives, Applied Geography. 29 (2009) 49-62. doi:10.1016/j.apgeog.2008.07.005.

[38] M. Elliott, S.J. Boyes, D. Burdon, Integrated marine management and administration for an island state-the case for a new Marine Agency for the UK, Marine Pollution Bulletin. 52 (2006) 469-474.

[39] Atkins, ICZM in the UK : A Stocktake, (2004). http://archive.defra.gov.uk/environment/marine/documents/protected/iczm/st-fullreport.pdf.

[40] Marine and Coastal Access Act, 2009. http://www.legislation.gov.uk/ukpga/2009/23/contents (accessed December 10, 2013).

[41] Natural England, Marine Strategy Framework Directive, (2013). http://www.naturalengland.org.uk/ourwork/marine/protectandmanage/strategyframe workdirective/default.aspx (accessed January 2, 2014).

[42] Department for Environment Food and Rural Affairs, Biodiversity 2020: A strategy for England's wildlife and ecosystem services, (2011).

[43] S. Fletcher, Representing stakeholder interests in partnership approaches to coastal management: Experiences from the United Kingdom, Ocean \& Coastal Management. 50 (2007) 606-622. doi:10.1016/j.ocecoaman.2006.09.006.

[44] T. Stojanovic, N. Barker, Improving governance through local Coastal Partnerships in the UK, Geographical Journal. 174 (2008) 344-360. doi:10.1111/j.14754959.2008.00303.x. 
[45] Coastal Partnerships Network, Baseline report for developing partnership working at the coast, (2013). www.marinemanagement.org.uk/marineplanning/key/documents/cpn_baselinereport. pdf (accessed September 4, 2013).

[46] S. Fletcher, R. Jefferson, G. Glegg, L. Rodwell, W. Dodds, England's evolving marine and coastal governance framework, Marine Policy. 45 (2014) 261-268. doi:10.1016/j.marpol.2013.09.007.

[47] S. Fletcher, Influences on stakeholder representation in participatory coastal management programmes, Ocean \& Coastal Management. 50 (2007) 314-328. doi:10.1016/j.ocecoaman.2006.11.003.

[48] Coastal Partnerships Network, Coastal Partnerships Network, (n.d.). http://www.coastalpartnershipsnetwork.org.uk/ (accessed August 13, 2018).

[49] Department of the Environment, Transport and the Regions, Research into integrated coastal planning in the North West region, DETR, 2000.

[50] North West Coastal Forum, Forum History | North West Coastal Forum, North West Coastal Forum. (2013). http://www.nwcoastalforum.org.uk/about/forum-history/ (accessed October 18, 2013).

[51] NWCF, Forum History | North West Coastal Forum, (2018). http://www.nwcoastalforum.org.uk/about/forum-history/ (accessed August 13, 2018).

[52] North West Coastal Forum, Understanding the Coastal Communities of the North West, (2009). http://www.nwcoastalforum.org.uk/resources/understanding-thecoastal-communities-of-the-north-west/ (accessed September 10, 2018).

[53] J.R. Clark, Coastal zone management for the new century, Ocean \& Coastal Management. 37 (1997) 191-216. doi:10.1016/S0964-5691(97)00052-5.

[54] R. Costanza, F. Andrade, P. Antunes, M. van den Belt, D. Boesch, D. Boersma, F. Catarino, S. Hanna, K. Limburg, B. Low, M. Molitor, J.G. Pereira, S. Rayner, R. Santos, J. Wilson, M. Young, Ecological economics and sustainable governance of the oceans, Ecological Economics. 31 (1999) 171-187. doi:10.1016/S0921-8009(99)00077-4.

[55] J. Areizaga, M. Sanò, R. Medina, J. Juanes, Improving public engagement in ICZM: A practical approach, Journal of Environmental Management. 109 (2012) 123-135. doi:10.1016/j.jenvman.2012.05.006.

[56] K.L. Yates, Meaningful stakeholder participation in marine spatial planning with offshore energy, 2017. doi:10.4324/9781315666877.

[57] T. Stojanovic, D.R. Green, G. Lymbery, Approaches to knowledge sharing and capacity building: the role of local information systems in marine and coastal management, Ocean \& Coastal Management. 53 (2010) 805-815.

[58] D.J. McGlashan, Funding in integrated coastal zone management partnerships, Marine Pollution Bulletin. 46 (2003) 393-396. doi:10.1016/S0025-326X(02)00257-6.

[59] S. Bremer, 'No right to rubbish': Mobilising post-normal science for planning Gisborne's wastewater outfall, Marine Policy. 46 (2014) 22-30. doi:10.1016/j.marpol.2014.01.001.

[60] T.N. Bauer, L. Aiman-Smith, Green career choices: The influence of ecological stance on recruiting, Journal of Business and Psychology. 10 (1996) 445-458. 